
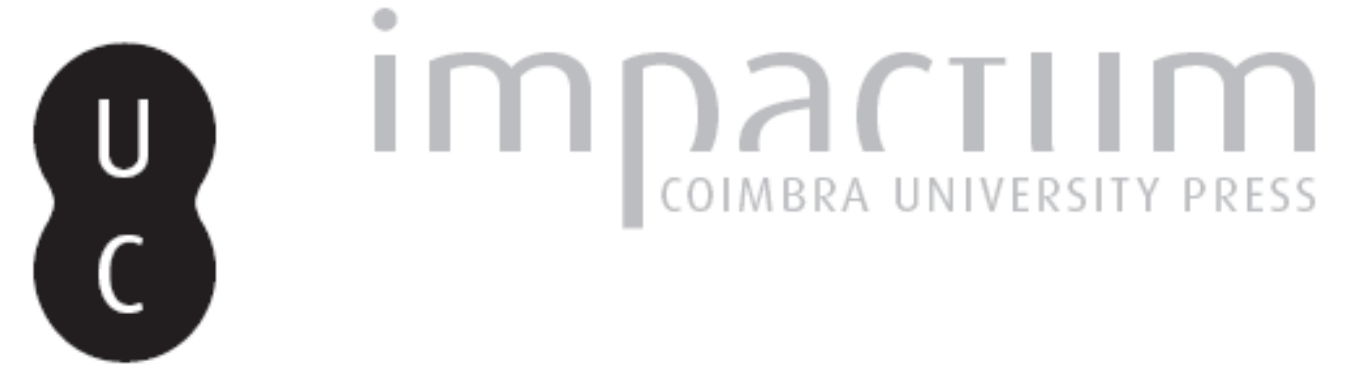

\title{
Bioarqueologia em Serpa: o caso da necrópole do Alpendre dos Lagares
}

\author{
Autor(es): $\quad$ Cunha, Eugénia
}

Publicado por: Imprensa da Universidade de Coimbra

URL persistente:

URI:http://hdl.handle.net/10316.2/45366

DOI:

DOI:https://dx.doi.org/10.14195/1647-8657_40_10

Accessed : $\quad$ 26-Apr-2023 11:44:38

A navegação consulta e descarregamento dos títulos inseridos nas Bibliotecas Digitais UC Digitalis, UC Pombalina e UC Impactum, pressupõem a aceitação plena e sem reservas dos Termos e Condições de Uso destas Bibliotecas Digitais, disponíveis em https://digitalis.uc.pt/pt-pt/termos.

Conforme exposto nos referidos Termos e Condições de Uso, o descarregamento de títulos de acesso restrito requer uma licença válida de autorização devendo o utilizador aceder ao(s) documento(s) a partir de um endereço de IP da instituição detentora da supramencionada licença.

Ao utilizador é apenas permitido o descarregamento para uso pessoal, pelo que o emprego do(s) título(s) descarregado(s) para outro fim, designadamente comercial, carece de autorização do respetivo autor ou editor da obra.

Na medida em que todas as obras da UC Digitalis se encontram protegidas pelo Código do Direito de Autor e Direitos Conexos e demais legislação aplicável, toda a cópia, parcial ou total, deste documento, nos casos em que é legalmente admitida, deverá conter ou fazer-se acompanhar por este aviso.

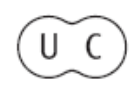


UNIVERSIDADE DE COIMBRA

FACULDADE DE LETRAS



CONIMBRIGA

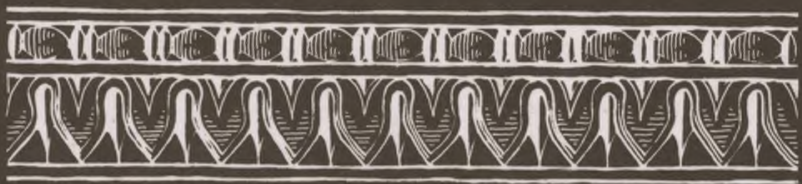

VOLUME XL - 2001 


\section{EUGÉNIA CUNHA ${ }^{1}$}

Professora Associada

Departamento de Antropologia, Faculdade de Ciências e Tecnologia

Universidade de Coimbra, 3000-056 Coimbra

e-mail: cunhae@ci.uc.pt

\section{BIOARQUEOLOGIA EM SERPA: O CASO DA NECRÓPOLE DO ALPENDRE DOS LAGARES. \\ "Conimbriga" XL (2001) p. 321-327}

RESUMO: Apresentam-se os dados antropológicos mais relevantes da análise de um pequeno conjunto de esqueletos recuperados durante a intervenção arqueológica no lugar de Alpendre dos Lagares (Serpa). Trata-se de uma amostra antropológica interessante não só por se tratar de um pequeno núcleo alto-medieval, mas também pelas características paleobiológicas dos indivíduos em análise passíveis de nos revelarem aspectos importantes das sua vidas. São feitas algumas comparações com séries antropológicas coevas.

ABSTRACT: The more relevant anthropological results retrieved for a small population nucleus, from the beginning of Middle Ages, are given. It concerns a series of skeletons exhumed from Alpendre dos Lagares (Serpa), during archaeological fieldwork. The importance of this small series relies on the paleobiological characteristics of the individuals themselves, who are susceptible to inform about patterns of life during the early Middle Ages. Some comparisons with other Portuguese osteological series from the same period are provided.

1 A análise antropológica laboratorial da presente série osteológica foi feita, também, pelo biólogo Rui Pedro Gama. A concretização deste estudo teve o apoio financeiro do IN AG.

Conimbriga, 40 (2001) 319-325 
(Página deixada propositadamente em branco) 


\section{B IO ARQUEOLOGIA EM SERPA: O CASO DA NECRÓPOLE DO ALPENDRE DOS LAGARES.}

\section{Introdução}

Durante muitos anos os esqueletos desempenharam um papel marginal na arqueologia. Tanto em contextos pré-históricos como históricos, são múltiplos os exemplos em que os restos ósseos eram considerados irrelevantes e, por isso, menosprezados. No entanto, desde o inicio da década de 80, tornou-se evidente que os arqueólogos incorparavam, cada vez mais, o estudo dos esqueletos nas suas pesquisas arqueológicas (Larsen, 1997). Em Portugal, esta tendência verificou-se urna década mais tarde. Efectivamente, nestes últimos dez anos, os arqueólogos recorrem significativamente mais ao trabalho do antropólogo. A comprová-lo estão as várias séries pré-históricas e, sobretudo, historicas que têm vindo a ser entegues para estudo à equipa do Laboratório de Paleodemografia e Paleopatologia do Departamento de Antropologia da Universidade de Coimbra. Este facto evidencia o reconhecimento do potencial dos ossos e dos dentes humanos para a reconstrução da vida, o que constitui o objecto primordial duma ciência recém emergente, a bioarqueologia ( Larsen, 1997).

No presente artigo referem-se, precisamente, as principais conclusões da análise paleobiológica de um pequeno conjunto de esqueletos recuperados durante a intervenção arqueológica no lugar do Alpendre dos Lagares, Serpa, da responsabilidade da arqueóloga Doutora Conceição Lopes. No decorrer desta escavação foram detectadas sete sepulturas com uma tipologia e enquadramento que apontavam para uma cronologia visigótica. Esta cronologia foi confirmada pela datação por ${ }^{14} \mathrm{C}$ do material ósseo de uma das sepulturas, efectuada na Universidade de Washington, que indicou tratar-se de material dos séculos VI a VIII.

Conimbriga, 40 (2001) 319-325 
Um pequeno núcleo populacional alto-medieval de Serpa: algumas considerações antropobiológicas.

Das sete sepulturas foram exumados oito esqueletos que, em Julho de 1996, foram entregues ao Laboratório supra citado para análise paleobiológica.

O presente texto reporta-se, apenas, à análise antropológica laboratorial do espólio osteológico. Para qualquer informação relativa à escavação, nomeadamente, do âmbito da antropologia funerária e tipología das inumações, remetemos para Lopes (1997).

Tabela 1 - Esqueletos exumados na Necrópole de Alpendre dos Lagares.

Resumo das principais características demográficas, morfológicas e patológicas.

\begin{tabular}{|c|c|c|c|c|c|c|}
\hline Sepultura & Idade & Sexo & $\begin{array}{l}\text { Estatura } \\
\text { (Olivier } \text { et al.,1978) }\end{array}$ & Robustez & Patologias & Observações \\
\hline 2 & 9-12 meses & & & & Sem & \\
\hline 3 & $40-45$ anos & Masculino & $1.62 \mathrm{~m}$ & Muito robusto & $\begin{array}{l}\text { Reabsorção } \\
\text { alveolar } \\
\text { Dish possível } \\
\text { Aitrose membro } \\
\text { superior }\end{array}$ & $\begin{array}{l}\text { Desgaste } \\
\text { dentário } \\
\text { considerável }\end{array}$ \\
\hline$\overline{4}$ & Mais de 50 anos & Masculino & 1.70 & Robusto & $\begin{array}{l}\text { Artrose anca } \\
\text { Dish eventual } \\
\text { Entesopatias }\end{array}$ & $\begin{array}{l}\text { Esqueleto } \\
\text { incompleto. } \\
\text { Não foram } \\
\text { recuperados } \\
\text { dentes } \\
\end{array}$ \\
\hline 5. esqueleto 1 & $40-50$ anos & Indeterminado & & & Cáries & $\begin{array}{l}\text { Esqueleto } \\
\text { incompleto } \\
\text { Desgaste den- } \\
\text { tário moderado }\end{array}$ \\
\hline 5. esqueleto 2 & $20-30$ anos & Feminino & $1.56 \mathrm{~m}$ & Pouco robusto & Abcesso anterior & $\begin{array}{l}\text { A datação foi } \\
\text { feita neste indi- } \\
\text { víduo }\end{array}$ \\
\hline 6 & $45-65$ anos & Masculino & $1.62 \mathrm{~m}$ & Robusto & 5 cáries & \\
\hline 7 & $40-50$ anos & Masculino & & Robusto & $\begin{array}{l}\text { Espondilolise } \\
\text { Perda de dentes } \\
\text { ante-mortem }\end{array}$ & $\begin{array}{l}\text { Desgaste } \\
\text { dentário } \\
\text { acentuado }\end{array}$ \\
\hline Sondagem 10 & 30-40 anos & Masculino & $1.64 \mathrm{~m}$ & Bastante robustc & $\begin{array}{l}\text { Cáries } \\
\text { Abcesso } \\
\text { Perda ante- } \\
\text {-mortem }\end{array}$ & $\begin{array}{l}\text { Desgaste } \\
\text { dentário } \\
\text { anterior }\end{array}$ \\
\hline
\end{tabular}

Conimbriga, 40 (2001) 319-325 
Das sete sepulturas só uma, a número 5, parece ter sido reutilizada: contém 2 esqueletos. Todas as outras serviram de local de inumação a apenas um indivíduo. A presente amostra é assim composta por 8 esqueletos medianamente conservados, 7 adultos e 1 não adulto. Dos 7 esqueletos adultos, 5 são homens, 1 é do sexo feminino sendo que o restante não permitiu a diagnose sexual. Todos os indivíduos masculinos são bastante robustos e de estatura média a baixa. Dos casos patológicos analisados, merece destaque a possibilidade de doença hiperostótica nos esqueletos 3 e 4 , ambos masculinos. É também de assinalar a frequência significativa de patologias orais: as cáries e os abcessos são comuns, o que denota uma alimentação rica em alimentos cariogénicos, tais como frutos doces e mel e, simultaneamente, a ausência de qualquer tipo de cuidados higiénicos e/ou terapêuticos com a dentição.

\section{Algumas comparações com séries coevas}

Não obstante a presente série osteológica poder ser comparada com outras séries portuguesas mais ou menos coevas, como é o caso da proveniente da necrópole paleocristã do assento de Chico Roupa (séculos VI-VII) (Soares et al., 1997) em Serpa, da de Santa Justa, também em Serpa, da necrópole visigótica de Torre de Palma (séculos IV-VIII) (Powell, 1996) e da necróple visigótica da Silveirona (Lopes, 1997 e Lopes e Cunha, 1998), no todo, o conjunto de indivíduos altomedievais ainda não é significativo, em termos numéricos, para permitir ilações a nível geral. Assim, só as séries da Silveirona e de Torre de Palma são constituídas por um número razoável de indivíduos, respectivamente $\mathrm{N}=53$ e $\mathrm{N}=63$, estando a última série ainda numa fase preliminar de análise. Cada um dos restantes sítios fornece, em média, menos do que 10 indivíduos. No entanto, são possíveis alguns comentários de carácter comparativo.

A reutilização das sepulturas é um dado comum entre as várias necrópoles, nomeadamente nas três da área de Serpa, Chico Roupa, a presente e ainda Santa Justa. Outro aspecto semelhante tem a ver com a fraca representatividade dos não-adultos, particularmente dos muito novos. Em Silveirona (Lopes, 1997) há cerca de $15 \%$ de não-adultos e em Torre de Palma (Powell, 1996) esta frequência atinge os 20\%. Já em Chico Roupa as crianças estão ausentes. A fraca representatividade 
dos esqueletos não-adultos parece indicar que os mesmos poderiam ser alvo de enterramento noutro local, como por exemplo nas áreas residenciais, ou que seriam enterrados numa área seleccionada do cemitério.

Em termos morfológicos, as estaturas até agora obtidas para os indivíduos alto-medievais são muito semelhantes, indicando valores medianos a baixos. Um aspecto curioso tem a ver com o acentuado desgaste dentário anterior, nalguns indivíduos maior que o posterior, nomeadamente na presente necrópole, facto que poderá estar relacionado com algum hábito cultural como o da utilização da boca para outros fins que não os alimentares.

A obtenção de resultados menos preliminares está dependente da continuação da análise antropológica da série de Torre de Palma e também da pequena amostra de Santa Justa. Será então possível empreender uma análise comparativa mais exaustiva que certamente contribuirá para o conhecimento das populações alto-medievais do Alentejo.

\section{BIBLIOGRAFIA}

CunHA, E. Gama, R.P. 1997. Alpendre dos Lagares (Serpa). Relatório antropológico. Departamento de Antropologia. Universidade de Coimbra. Inédito.

LARSEN, C.S. 1997. Bioarcheology. Interpreting behavior from the human skeleton. Cambridge. Cambridge University Press.

LOPES, C. 1997. Silveirona revisitada. Nova análise antropológica quatro décadas depois. Relatório de estágio em Ciências Humanas. Departamento de Antropologia. Universidade de Coimbra. Inédito.

LOPES, C.; Cunha, E. 1998. Silveirona revisited: a new anthropological analysis of a visigothic population. Actas do X Congreso Español de Antropologia Biologica.

MERBS, C. 1989. Spondylolysises nature and anthropological significance. International Journal of Anthropology. 4.3:163-169.

OLIVIER, G. et al. 1978. New estimations of stature and cranial capacity in modern man. Journal of Human Evolution. 7:512-518.

Powell, M. 1996. Life and death at Torre de Palma, Alto Alentejo, Portugal. Paper presented at the symposium "Fifteen years at Torre de Palma" University of Louisville.

SoARes, A.M.; SANTOS, A.L.; Umbelino, C. 1997. A Necrópole Paleocristã do Assento de Chico Roupa (Vila Verde de Ficalho, Serpa). Arqueologia Medieval. 5: 23-33.

Conimbriga, 40 (2001) 319-325 